\title{
Pelatihan Test of English Proficiency bagi Dosen di Universitas Prof. Dr. Hazairin, SH Bengkulu
}

\section{Workshop of Test of English Proficiency on Lecturers of Universitas Prof. Dr. Hazairin, SH Bengkulu}

\author{
Elva Utami*, Lisa Rakhmanina
}

Prodi Pendidikan Bahasa Inggris Universitas Prof Dr Hazairin SH, Jalan Ahmad Yani No. 1 Bengkulu, Indonesia

\begin{tabular}{l}
\hline Info Artikel \\
\hline Diterima 28 Agustus 2019 \\
Ditelaah 27 Desember 2019 \\
Disetujui 01 Januari 2020 \\
Tersedia daring 03 Januari 2020 \\
*Penulis untuk korespondensi \\
utamielva80@ gmail.com \\
\hline \\
Kata Kunci: \\
Diskusi, \\
Dosen, \\
Pelatihan, \\
TOEP \\
\end{tabular}

Keywords:

Discussion,

Lecturer,

Workshop,

TOEP

\begin{tabular}{l} 
ABSTRAK \\
\hline Kegiatan pengabdian masyarakat ini bertujuan untuk meningkatkan kemampuan test of \\
english proficiency (TOEP) dosen Universitas Prof. Dr. Hazairin, SH dengan melatih \\
keterampilan mendengar (listening) dan membaca (reading). Selain itu, kegiatan ini \\
memberikan wawasan kepada peserta tentang cara mudah atau tips dan trik ketika \\
berhadapan dengan soal listening dan reading dalam TOEP dengan tujuan untuk \\
meningkatkan skor TOEP peserta. Metode yang digunakan adalah ceramah, \\
diskusi/tanya jawab, dan praktik. Peserta yang menjadi target pelatihan ini adalah dosen \\
yang belum lulus sertifikasi dosen. Pre-test pada awal kegiatan dan post-test pada akhir \\
kegiatan dilaksanakan sebagai instrumen untuk mengevaluasi kegiatan pengabdian. \\
Hasil kegiatan pengabdian ini menunjukkan bahwa ada perbedaan dalam skor \\
kemampuan peserta pelatihan sebelum dan sesudah pelatihan. Hasil pre-test \\
menunjukkan bahwa skor maksimum untuk TOEP adalah 405, skor rata-rata adalah \\
266,5 dan skor minimum adalah 205. Sedangkan hasil post-test menunjukkan bahwa \\
skor maksimum untuk TOEP peserta adalah 465, skor rata-rata adalah 393,5 dan skor \\
minimum adalah 360. Peningkatan skor TOEP peserta ini menunjukkan bahwa pelatihan \\
kegiatan ini berhasil.
\end{tabular}
kegiatan ini berhasil.

\section{ABSTRACT}

This community service was aimed to improve the ability of the test of english proficiency (TOEP) the lecturers of Prof. Dr. Hazairin, SH University by practicing listening and reading skills. In addition, this activity was provided participants with insight into easy ways or tips and tricks when dealing with listening and reading questions in the TOEP with the aimed of increasing the participant's TOEP score. The method used were lecture, discussion/question and answer, and practice. Participants who were the target of this training were lecturers who had not yet passed the lecturer certification. Pre-test at the beginning of the activity and post-test at the end of the activity carried out as an instrument for evaluating community service activities. The results of these community service activities indicated that there were differences in the ability scores of the trainees before and after the training. The pre-test results showed that the maximum score for TOEP was 405, the average score was 266.5 and the minimum score was 205. While the post-test results showed that the maximum score for participants' TOEP was 465 , the average score was 393.5 and the minimum score was 360. Increasing the participant's TOEP score showed that the training activity was successful.

ISSN 2685-0354 (Media Online). Diterbitkan oleh Universitas Prof. Dr. Hazairin, SH. Ini merupakan jurnal bebas akses di bawah lisensi Creative Commons Atribution 4.0 International (https://creativecommons.org/licenses/by/4.0

\section{PENDAHULUAN}

Tes adalah suatu metode pengukuran performa terhadap kemampuan dan pengetahuan seseorang (Brown, 2004). Dalam tes sertifikasi dosen (serdos), ada banyak ketentuan yang berlaku yang harus dilewati oleh para dosen peserta serdos agar lulus dalam tes serdos tersebut, diantaranya adalah adalah lulus Test of English Proficiency 
(TOEP). TOEP merupakan tes kemahiran Bahasa Inggris (The Association of Teaching English as Foreign Language in Indonesia [TEFLIN], 2013). Tes ini mengukur tingkat kemampuan seseorang dalam bidang kemahiran Bahasa Inggris dan terbebas dari kurikulum. TOEP bisa diikuti oleh semua pihak yang mau mengetahui tingkat kemahiran berbahasa Inggrisnya.

Eligibilitas dosen di Pangkalan Data Pendidikan Tinggi (PDPT) merupakan kesempatan yang sangat besar bagi dosen untuk ikut tes/seleksi serdos (Dharmawati \& Mardiana, 2019). Data yang diperoleh dari Bagian Kepegawaian Universitas Prof. Dr. Hazairin, SH (Unihaz) menunjukkan sebanyak 78 orang dosen Unihaz telah lulus serdos dari 141 orang dosen aktif. Sisanya sebanyak 63 orang dosen belum memiliki sertifikat pendidik. Sebanyak 29 orang dari 63 orang yang belum tersertifikasi tersebut telah masuk kembali dalam data yang layak ikut seleksi serdos pada tahun 2019.

Soal TOEP untuk tes serdos terdiri atas 50 butir soal listening yang berlangsung selama 45-50 menit dan 50 butir soal reading yang berlangsung selama 60 menit (TEFLIN, 2013; Phillips, 2001). Para peserta tes TOEP harus mencapai skor minimal 4 agar berada pada titik aman untuk dinyatakan lulus dalam nilai gabungan sebagai syarat serdos.

Berdasarkan hasil wawancara dengan dosen-dosen yang belum lulus serdos, sebagian besar penyebab ketidaklulusan adalah nilai TOEP yang belum mencukupi. Mereka kesulitan memahami dan menjawab soal-soal berbahasa inggris. Oleh karena itu, suatu pelatihan TOEP sangat perlu dan mendesak dilaksanakan sebagai solusi untuk meningkatkan kemampuan penguasaan Bahasa Inggris bagi dosen-dosen yang belum tersertikasi di Unihaz.

Materi pelatihan yang diberikan dapat berupa lisan (listening) dan tertulis (reading) yang sangat berguna untuk persiapan dosen-dosen dalam menghadapi tes TOEP. Kedua skill tersebut merupakan elemen penting yang diujikan dalam tes TOEP sebagai persyaratan serdos. Kemahiran berbahasa Inggris dalam tes ini adalah kemahiran yang terwujud dalam keberhasilan menjawab sejumlah pertanyaan tentang makna yang diungkapkan lewat listening dan reading (TEFLIN, 2013). Soal listening dalam tes TOEP bertujuan untuk menguji kemampuan dalam memahami bahasa lisan (Samosir, Ariansyah, Christian, Ahmat, \& Reginawati, 2017). Kemampuan listening merupakan hal yang sangat penting dalam pembelajaran Bahasa Inggris sehingga peserta diharapkan dapat memiliki kemampuan memahami teks-teks yang bersifat audio yang merupakan bagian komunikasi sehari-hari yang sangat dominan (Syafii, 2016). Soal-soal bagian listening hanya satu kali diucapkan/dibacakan atau tidak dapat diulang lagi. Peserta tidak dapat kembali lagi ke soal sebelumnya apabila telah beralih ke nomor soal berikutnya. Tidak akan ada perbaikan jawaban.

Dalam mengerjakan soal-soal reading, peserta dapat kembali ke soal-soal sebelumnya dalam rentang waktu yang masih tersedia. Perbaikan jawaban soal yang pernah dikerjakan dapat dilakukan jika dikehendaki. Reading comprehension bertujuan untuk menguji kemampuan dalam memahami bahasa tulisan (Samosir et al., 2017). Dalam memahami suatu teks, pembaca harus menggunakan 'reading techniques' seperti: "sensitizing by inferencing through the context and word-formation understanding realtions within the sentence, linking sentences and idea through reference and link-words" (Grellet, 1995). Faktor lain yang terlibat dalam membaca adalah predicting, previewing, anticipating, skimming dan scanning (Herwandar, Safryono, \& Haryono, 2012).

Persoalan prioritas yang disepakati oleh pengabdi dan mitra untuk diselesaikan melalui program pengabdian pada masyarakat ini adalah meningkatkan kemampuan TOEP dosen-dosen Unihaz khususnya dosen-dosen yang belum di sertifikasi. Program ini dirancang agar mereka lebih siap dalam menghadapi tes TOEP yang dilaksanakan oleh Pusat Layanan Tes Indonesia (PLTI).

\section{METODE}

Program ini di laksanakan selama 3 bulan yaitu dari bulan April - Juli 2019 yang terdiri dari 10 kali pertemuan. Dua pertemuan untuk melaksanakan pre-test dan post-test, 6 pertemuan tatap muka untuk pelatihan TOEP dan 2 pertemuan untuk pembelajaran tips dan trik dalam menjawab soal TOEP untuk kemampuan listening dan reading. Satu kali pertemuan tatap muka berlangsung selama 60 menit. Kegiatan pelatihan ini dilaksanakan setiap hari Rabu jam 13.00-14.00 WIB di ruang G1 gedung Fakultas Keguruan dan Ilmu Pendidikan (FKIP) Unihaz. Pelaksanaan kegiatan pelatihan TOEP terbagi dalam beberapa tahapan yaitu studi pendahuluan, penyusunan materi pelatihan dan pelaksanaan pelatihan.

\section{Studi Pendahuluan}

Sebelum pelaksanaan kegiatan, tim terlebih dahulu melakukan studi pendahuluan melalui wawancara dan observasi. Wawancara dan observasi ini dilakukan untuk memperoleh data dan gambaran tentang kondisi mitra. 


\section{Penyusunan Materi Pelatihan}

Materi dalam kegiatan pelatihan ini sangat diperlukan oleh mitra karena merupakan bahan dasar dan awal untuk menguasai suatu keterampilan. Dalam pelatihan ini, tim pengabdian mengadopsi materi dari beberapa sumber yang akan dibagi menjadi dua jenis materi yaitu 1) penjelasan umum tentang TOEP dan strategi dalam menguasai listening dan reading, 2) soal latihan dan pembahasannya. Pemberian materi, latihan soal, dan evaluasi diharapkan dapat meningkatkan pemahaman pengetahuan, dan kemampuan bahasa inggris mitra (Wijayanti \& Miqawati, 2016).

\section{Pelaksanaan Pelatihan}

Metode yang digunakan adalah metode ceramah dan praktek. Peserta tidak hanya diberikan materi pada saat pelatihan tetapi juga diberikan soal-soal latihan serta tips dan trik pengerjaan soal listening dan reading. Metode yang digunakan ini sejalan dengan yang dilakukan oleh Sagala, Supriyono, Sutardi, dan Prihanani (2019) dan Samosir et al., (2017) yaitu metode ceramah dan metode pendampingan (mentoring).

\section{HASIL DAN PEMBAHASAN}

Sasaran peserta pelatihan TOEP adalah dosen-dosen yang belum disertifikasi di lingkungan Unihaz. Tim pengabdian melakukan survei dan sosialisasi terlebih dahulu ke setiap program studi yang ada di Unihaz. Sebanyak 10 orang mendaftar untuk ikut pelatihan yang ditawarkan. Mereka dari berbagai program studi yaitu Bimbingan dan Konseling, Pendidikan Geografi, Manajemen, Akutansi, Ilmu Ekonomi dan Studi Pembangunan, dan Ilmu Hukum. Jumlah yang mendaftar ini tergolong sedikit dibandingkan dengan jumlah dosen yang belum memiliki sertifikat pendidik yaitu 35\% dari jumlah dosen yang eligible di PDPT untuk tahun 2019 dan 16\% dari total dosen Unihaz yang belum memiliki sertifikasi pendidik. Hal ini disebabkan oleh sewaktu kegiatan pengabdian dilaksanakan sebagian dosen yang belum memiliki sertifikat pendidikan tersebut baru saja selesai mengisi form D5 pada proses serdos 2019 dan mereka sedang menantikan pengumuman kelulusan.

Pre-test dilakukan kepada para peserta pada pertemuan pertama dengan tujuan mengetahui skor TOEP awal peserta (Gambar 1). Pre-test dilaksanakan selama 1 jam 50 menit. Peserta mengerjakan 50 butir soal listening selama 50 menit dan 50 butir soal reading selama 60 menit. Rata-rata nilai pre-test TOEP yang diperoleh oleh para peserta masih jauh dari standar yaitu 266,5 dengan nilai tertinggi 405 (Tabel 1). Tes TOEP ini tidak ada nilai lulus atau tidak lulus, melainkan nilai yang dihasilkan akan dibobotkan sesuai dengan buku panduan yang disediakan oleh panitia serdos (Hanafi et al., 2019). Misalnya, seseorang mendapat nilai TOEP 500 akan mendapatkan nilai 4 apabila dikonversikan atau nilai 6 untuk skor 660 .

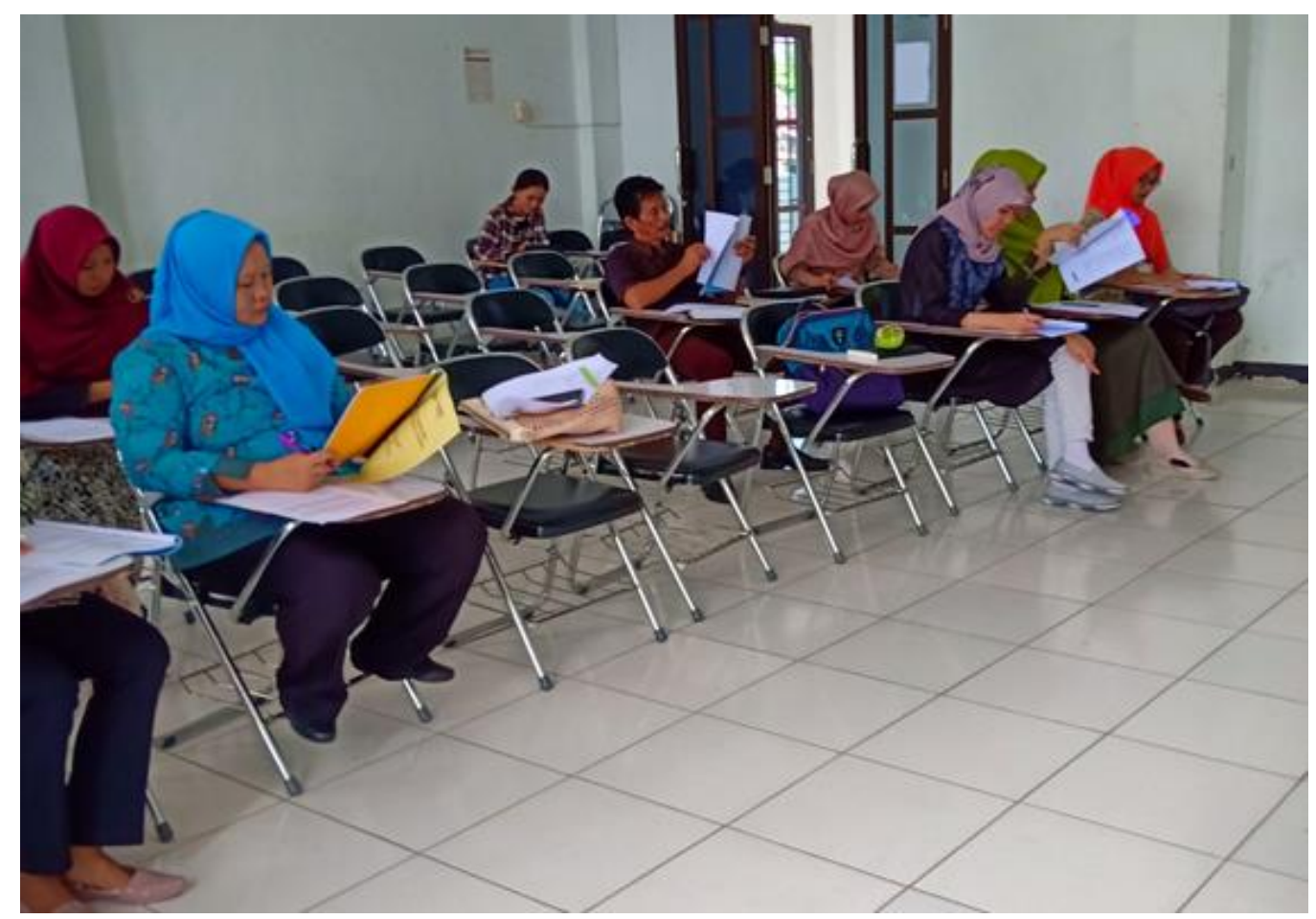

Gambar 1. Pelaksanaan pres-test 
Tabel 1. Hasil pre-test dan post-test TOEP

\begin{tabular}{|c|c|c|c|c|c|c|c|c|}
\hline \multirow{3}{*}{ No } & \multirow{3}{*}{$\begin{array}{l}\text { Inisial } \\
\text { peserta }\end{array}$} & \multicolumn{3}{|c|}{ Pre-test } & \multicolumn{3}{|c|}{ Post-test } & \multirow{3}{*}{ Progres } \\
\hline & & \multicolumn{2}{|c|}{ Kemampuan } & \multirow{2}{*}{ Skor TOEP } & \multicolumn{2}{|c|}{ Kemampuan } & \multirow{2}{*}{ Skor TOEP } & \\
\hline & & Listening & Reading & & Listening & Reading & & \\
\hline 1 & AS & 16 & 20 & 405 & 20 & 25 & 465 & $15 \%$ \\
\hline 2 & VP & 17 & 16 & 390 & 22 & 20 & 430 & $10 \%$ \\
\hline 3 & FA & 11 & 16 & 355 & 15 & 20 & 405 & $14 \%$ \\
\hline 4 & $\mathrm{HH}$ & 12 & 12 & 340 & 17 & 16 & 390 & $15 \%$ \\
\hline 5 & IA & 17 & 4 & 330 & 21 & 10 & 370 & $12 \%$ \\
\hline 6 & MR & 9 & 14 & 330 & 14 & 16 & 365 & $11 \%$ \\
\hline 7 & $\mathrm{AD}$ & 11 & 11 & 325 & 15 & 16 & 385 & $18 \%$ \\
\hline 8 & WK & 13 & 6 & 320 & 18 & 12 & 370 & $16 \%$ \\
\hline 9 & $\mathrm{NJ}$ & 10 & 12 & 320 & 15 & 18 & 395 & $23 \%$ \\
\hline \multirow[t]{2}{*}{10} & PR & 15 & - & 205 & 18 & 10 & 360 & $76 \%$ \\
\hline & & & Rerata skor & 266,5 & & Rerata skor & 393,5 & $48 \%$ \\
\hline
\end{tabular}

Hasil pre-test menunjukkan bahwa pelatihan ini sangat diperlukan. Pertemuan berikutnya dilaksanakan sesuai dengan kesepakatan jadwal antara tim pengabdi dengan mitra. Tim pengabdi menyusun materi untuk 10 kali pertemuan sebagai kurikulum acuan dalam pelatihan (Tabel 2). Materi yang diberikan dibagi dalam 2 skill yaitu listening dan reading. Pada pertemuan kedua, ketiga, dan keempat narasumber menjelaskan materi tentang listening. Peserta juga diberikan latihan soal listening (Gambar 2). Pada pertemuan kelima, keenam dan ketujuh narasumber memberikan materi tentang reading (Gambar 3). Setelah itu, pada pertemuan kedelapan dan kesembilan peserta diberikan tips dan trik menjawab soal TOEP dengan mudah.

Tabel 2. Jadwal Pelaksanaan Kegiatan Pelatihan

\begin{tabular}{cl}
\hline Pertemuan Ke- & Materi \\
\hline 1 & Pre- Test \\
2 & Listening \\
3 & Listening \\
4 & Listening \\
5 & Reading \\
6 & Reading \\
7 & Reading \\
8 & Tips and Trick \\
9 & Tips and Trick \\
10 & Post-Test
\end{tabular}

Ada tiga jenis percakapan pada kemampuan listening yaitu: percakapan pendek, percakapan panjang dan cerita panjang (Phillips, 2001). Percakapan pendek terdiri dari 2 baris dan dialog antara 2 pembicara. Terdapat 30 pertanyaan untuk jenis soal percakapan ini. Percakapan panjang terdiri dari 2 orang yang akan dipergunakan untuk menjawab pertanyaan dan akan ditemui beberapa kali tanya jawab antara kedua orang tersebut. Jumlah pertanyaan untuk setiap percakapan kurang lebih 7 pertanyaan. Cerita Panjang akan diperdengarkan yaitu seseorang bercerita tentang beberapa permasalahan. Pada setiap permasalahan akan diberikan pertanyaan. Jumlah pertanyaan pada bagian ini kurang lebih 3 sampai 7 pertanyaan. Reading merupakan suatu kumpulan cerita yang mempunyai tema. Pada bagian ini biasanya terdiri atas 50 soal dari 4 sampai 7 teks dengan waktu pengerjaan selama 55 menit.

Kedua listening dan reading ini mempunyai tingkat kesulitan masing-masing. Pada listening, peserta harus berkonsentrasi tinggi untuk mendengarkan percakapan yang diperdengarkan melalui headphone. Hal ini tentu menyulitkan bagi peserta yang belum terbiasa mendengarkan percakapan yang diucapkan oleh penutur asli (native speaker) yang terkadang ada yang menggunakan English British dan ada yang menggunakan English American. Oleh sebab itu, peserta memerlukan tips dan trik agar dapat menyiasati permasalahan tersebut. Demikain pula pada reading, 
peserta harus mampu menjawab 50 pertanyaan dalam durasi 55 menit. Untuk itu, peserta harus mempunyai kemampuan membaca cepat. Namun, peserta harus tetap teliti sehingga dapat menjawab pertanyaan dengan tepat dan benar. Pada skil reading juga diperlukan tips dan trik untuk menyiasatinya.

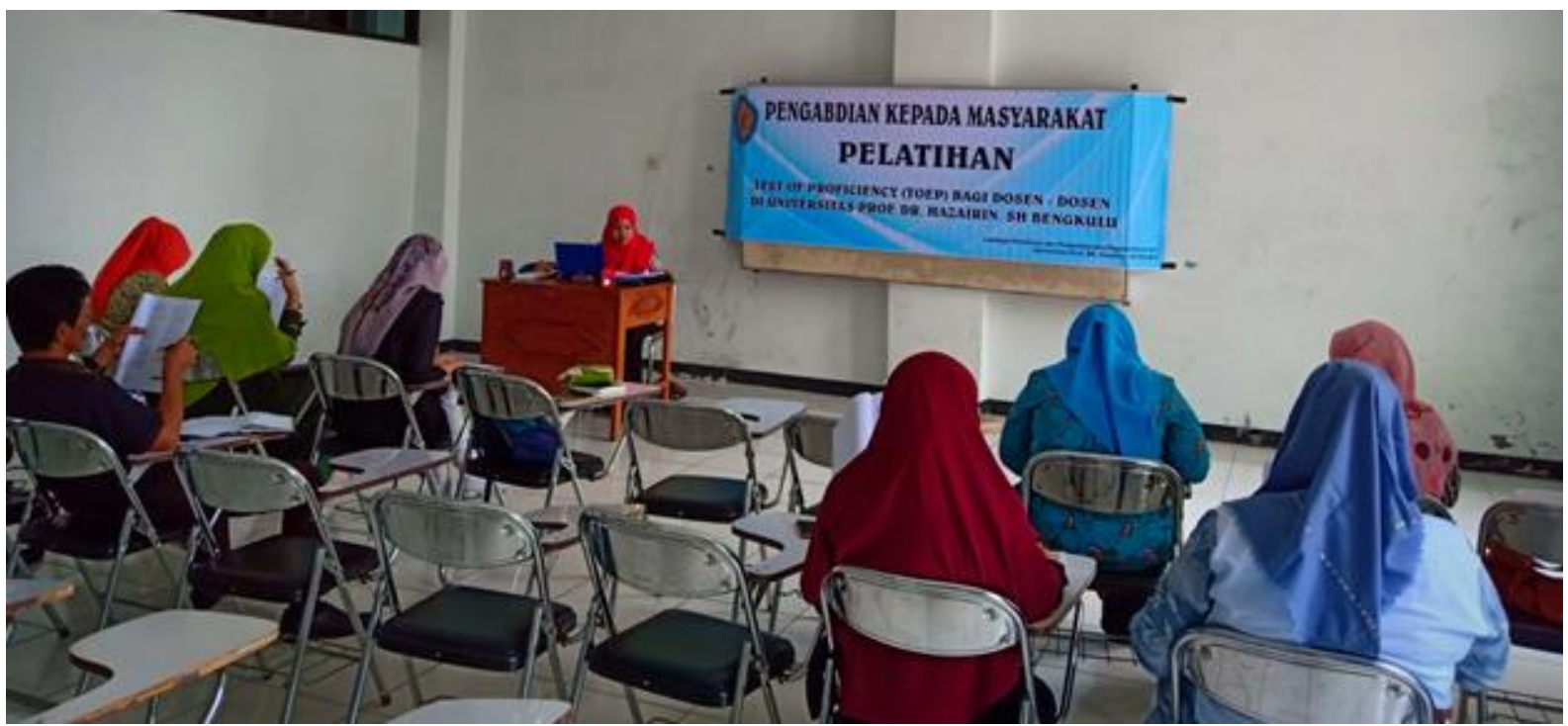

Gambar 2. Pemberian materi listening

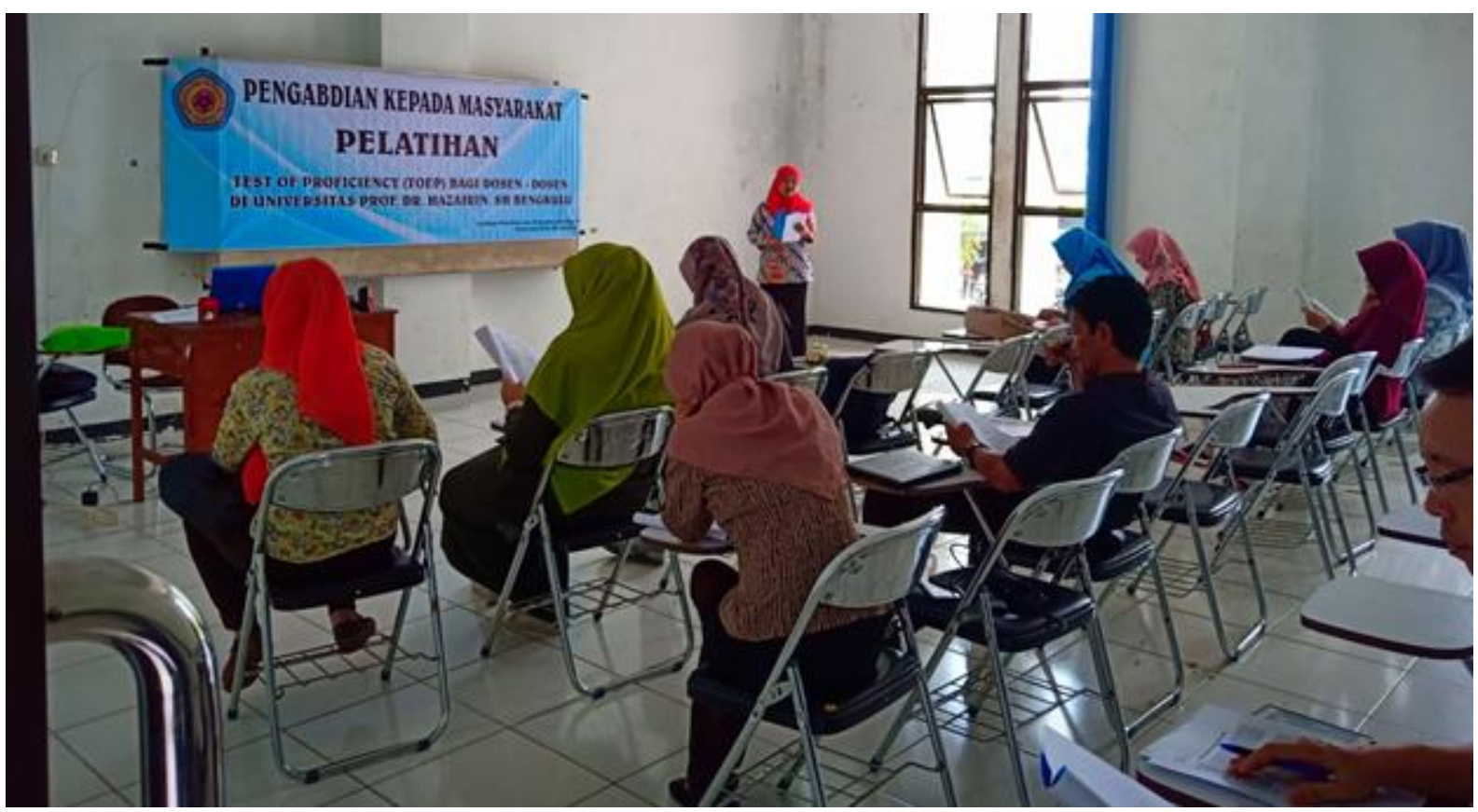

Gambar 3. Pemberian materi reading

Kegiatan pelatihan ini mendapatkan sambutan positif dari para peserta, terutama karena program ini sesuai dengan kebutuhan mereka. Bentuk sambutan positif tersebut antara lain terlihat dari partisipasi aktif dan baik dari peserta pelatihan. Mereka termotivasi dan antusias selama mengikuti pelatihan. Diskusi dan tanya jawab terjadi ketika ada bagian atau hal yang kurang dimengerti oleh peserta. Para peserta diberi kebebasan dalam bertanya agar peserta semakin memahami materi yang diberikan.

Dengan demikian dapat disimpulkan para peserta sangat antusias untuk meningkatkan kemampuan dan pemahaman TOEP mereka. Antusiasme ini juga tercermin dari peningkatan skor TOEP yang didapat oleh peserta pelatihan setelah mengikuti pelatihan selama 10 kali pertemuan ini. Setelah dilakukan post-test, maka data yang didapat menunjukan bahwa adanya perbedaan nilai rata-rata sebelum dan sesudah diberikan pelatihan. Nilai rata-rata pada pre-test yaitu 266,5 dengan nilai tertinggi 405 dan nilai terendah 205. Sedangkan nilai rata-rata (mean score) pada post-test mengalami peningkatan yaitu 393,5 dengan nilai tertinggi 465 dan nilai terendah 360 (Tabel 1). Dengan 
demikian dapat disimpulkan bahwa pelatihan TOEP bagi dosen-dosen dilingkungan Universitas Prof. Dr. Hazairin, SH Bengkulu berjalan sukses dan berhasil. Hal ini dapat dilihat dari peningkatan skor TOEP yang diperoleh oleh para peserta pelatihan.

\section{KESIMPULAN}

Berdasarkan hasil pelatihan TOEP yang telah dilaksanakan selama 10 kali pertemuan bagi dosen-dosen dilingkungan Universitas Prof. Dr. Hazairin, SH ini maka dapat disimpulkan bahwa pelatihan TOEP ini berjalan dengan sukses dan berhasil. Hal ini dapat dilihat dari hasil nilai rata-rata pre-test yaitu 266,5 meningkat menjadi 393,5. Dengan demikian pelatihan TOEP ini telah berhasil menjadi solusi atas masalah yang dihadapi oleh mitra. Kombinasi metode diskusi, tanya jawab dan praktik yang diterapkan oleh tim pengabdian dalam kegiatan pengabdian ini merupakan metode yang tepat karena dengan menerapkan metode ini masalah yang dihadapi mitra menjadi teratasi.

Mengingat pentingnya TOEP ini bagi dosen-dosen tidak hanya bagi yang akan ikut tes sertifikasi tapi juga bagi dosen-dosen yang akan melanjutkan pendidikan ke jenjang yang lebih tinggi, maka hendaknya para dosen dilingkungan Universitas Prof. Dr. Hazairin, SH Bengkulu untuk tetap mendalami materi TOEP ini.

\section{UCAPAN TERIMA KASIH}

Program Pengabdian Kepada Masyarakat ini didanai oleh Lembaga Penelitian dan Pengabdian Kepada Masyarakat, Universitas Prof. Dr. Hazairin, SH Bengkulu dengan Surat Perjanjian Nomor 55/A-5/LPPMUNIHAZ/IV/2019.

\section{DAFTAR PUSTAKA}

Brown, D. (2004). Language assessment : Principles and classroom practices. New York, USA: Pearson/Longman

Dharmawati, \& Mardiana. (2019). Aplikasi TOEP (test of english proficiency) berbasis android untuk sertifikasi dosen. Sinkron: Jurnal dan Penelitian Teknik Informatika, 2(2), 1-5.

Grellet, F. (1995). Developing reading skills: A practical guide to reading comprehension exercises. Cambridge, England: Cambridge University Press.

Hanafi, I., Kuswarno, E., Zainuddin, M., Rustad, S., Haroen, Y., Sugiarto, B., ... Tarigan, Y. (2019). Buku pedoman sertifikasi pendidik untuk dosen (Serdos) terintegrasi, Buku 2, Penilaian portofolio. Jakarta, Indonesia: Direktorat Jenderal Sumber Daya Ilmu Pengetahuan, Teknologi Dan Pendidikan Tinggi Kementerian Riset, Teknologi dan Pendidikan Tinggi.

Herwandar, R., Safryono, D. A., \& Haryono, P. Y. (2012). Evaluasi program matrikulasi "TOEFL" mahasiswa Universitas Al Azhar Indonesia 2010/2011. Jurnal Al-Azhar Indonesia Seri Humaniora, 1(3), 179-188.

Phillips, D. (2001). Longman complete course for the TOEFL test: Preparation for the computer and paper tests. London, England: Longman.

Sagala, D., Supriyono, Sutardi, D., \& Prihanani. (2019). Pelatihan dan pendampingan penulisan artikel ilmiah pada guru Sekolah Dasar di Kecamatan Air Periukan Kabupaten Seluma Provinsi Bengkulu. Abdihaz: Jurnal Ilmiah Pengabdian pada Masyarakat, 1(1), 1-8.

Samosir, H., Ariansyah, Christian, A., Josi, A., \& Reginawati, N. (2017). Pelatihan dan try-out Test of English as a Foreign Language (TOEFL) dengan sistem komputerisasi pada SMK Negeri 2 Prabumulih [Laporan Pengabdian kepada Masyarakat]. Prabumulih, Indonesia: Sekolah Tinggi Manajemen Informatika dan Komputer Prabumulih.

Syafii, L., \& Sugianto, A. (2017). Pelatihan bahasa inggris berekuivalensi TOEFL bagi Dosen Universitas Muhammadiyah Ponorogo. Adimas: Jurnal Pengabdian Kepada Masyarakat, 1(1), 25-30.

The Association of Teaching English as Foreign Language in Indonesia. (2013). Prosedur Operasi Baku (POB ) Test of English Proficiency (TOEP). Jakarta, Indonesia: The Association of Teaching English as Foreign Language in Indonesia (TEFLIN) bekerjasama dengan Direktorat Pendidik dan Tenaga Kependidikan Direktorat Jenderal Pendidikan Tinggi Kementeria Pendidikan dan Kebudayaan.

Wijayanti, F., \& Miqawati, A. H. (2016). Pelatihan test of english as a foreign language (TOEFL) ekuivalen anggota UKM E-Club Politeknik Negeri Jember. Dalam Prosiding Seminar Hasil Penelitian dan Pengabdian Masyarakat Dana BOPTN (hal. 177-180). Jember, Indonesia. 